Fifth International Conference on Sustainable Construction Materials and

Technologies. http://www.claisse.info/Proceedings.htm

\title{
EFFECT OF RECYCLED CONCRETE AGGREGATE ON THE SHEAR BEHAVIOR OF REINFORCED CONCRETE PANELS
}

\author{
Huan Zhang ${ }^{1}$, Katie Kuder ${ }^{2}$, Dawn Lehman ${ }^{3}$, Paolo Calvi ${ }^{4}$, and Charles Roeder ${ }^{5}$ \\ ${ }^{1}$ Room 206; School of Civil Engineering, Campus II; 73 Huanghe Road, Nangang \\ District; Harbin, P.R.; China, 150090; Harbin Institute of Technology \\ $290112^{\text {th }}$ Ave; Seattle, WA 98122-1090; kuderk@seattleu.edu; Seattle University; \\ Civil and Environmental Engineering \\ 3204 More Hall; Seattle, WA 98195; delehman@uw.edu; University of Washington; \\ Civil and Environmental Engineering \\ ${ }^{4} 201$ More Hall; Seattle, WA 98195; pmc85@uw.edu; University of Washington; Civil \\ and Environmental Engineering \\ ${ }^{5}$ More Hall; Seattle, WA 98195; croeder@uw.edu; University of Washington; Civil \\ and Environmental Engineering
}

\begin{abstract}
Due to its design versatility, availability, and cost efficiency, concrete continues to play a dominant role in the construction industry. Typical concrete production requires a significant amount of nonrenewable resources. One way to improve the sustainability of this material is to use recycled concrete aggregate (RCA) in place of virgin aggregate. The purpose of this study is to investigate the use of RCA in reinforced concrete panels. Three reinforced concrete panels were cast: normal concrete aggregate (NCA), 25\% RCA, 50\% RCA and 100\% RCA. The data show the compressive strength and elastic modulus of the concrete are reduced with increasing amount of RCA, while the tensile strength does not change significantly. For the reinforced concrete panels, the shear response is affected by inclusion of RCA, with a reduction in the initial stiffness and also an earlier observance of the first crack.
\end{abstract}

Keywords: Reinforced concrete, recycled concrete aggregate, concrete panels, normal concrete aggregate.

\section{INTRODUCTION}

The construction industry can cause problems related to the sustainability of our environment due to a variety of reasons, including emission of carbon dioxide (due to cement production), use of virgin materials (sand and rock), and landfilling of materials after demolition. This study focuses on improving the sustainability of concrete by including recycled concrete aggregate (RCA) in new concrete. Inclusion of RCA in concrete lessens the environmental impact by: (1) reducing or eliminating the amount of virgin aggregate required and (2) using waste materials that would otherwise be landfilled. 
In 2017, an estimated 53.2 billion tons of virgin construction aggregate was globally purchased (Rockproducts, 2018), and this excessive consumption of aggregate could cause a natural source shortage. On the other hand, a considerable amount of the construction and demolition waste $(\mathrm{CDW})$ is generated annually. It is estimated that 123 million tons of CDW is generated annually in the United States (Safiuddin et al., 2013), and that 200 million tons in generated China (Yang et al., 2018). The most common method for disposing of this waste is to bury it in landfills, which results in occupying land and presents other environmental problems (Radonjanin et. al, 2013). Using CDW to produce recycled aggregate presents an alternative to preserve natural resources and reduce the need for disposal (Xiao et. al, 2012).

Crushing waste concrete to produce aggregate started at the end of World War II, and the research on recycled aggregate concrete (RAC) began decades ago (Safiuddin et al., 2013; Dean et al., 2008). RAC is concrete in which some, or all, of the coarse aggregate is made from the recycled CDW. The CDW is crushed into smaller pieces and unwanted materials (plastics, steel, paper) are removed (by screening, vacuuming, and visual inspection). Based on the processing, the resulting aggregate can have a specified size and quality. To date, most research has focused on the coarse recycled aggregate (although fine aggregate - sand - can also be reclaimed from CDW) and is the material investigated in this study.

Although the concept of reusing CDW as recycled aggregate is not new; the usage of it in practice is limited because the incorporation of recycled aggregate typically reduces the mechanical performance and durability characteristics of concrete (Dean et al., 2008; Henry et al., 2011; Kou et al., 2011). Nevertheless, researchers have shown that RAC can be used. At lower replacement ratios (less than $30 \%$ of virgin aggregate replaced with recycled aggregate) research has shown that the mechanical properties of RAC are similar to those of normal concrete. Furthermore, even with $100 \%$ replacement of the virgin coarse aggregate, the RAC can meet the requirements for structural use (Corinaldesi, 2010).

RAC contains residual mortar that adheres to the recycled aggregate. It is hypothesized that this residual mortar is responsible for the inferior properties of RAC (Fathifazl et al., 2011; Fatjifazl et. al, 2009). In particular, the shear behavior of structural components with RAC is a concern for two reasons. First, the existence of the residual mortar makes the interfacial transition zone (ITZ), already the weakest phase of the concrete, even more complicated. The ITZ is the zone between the aggregate and the cement paste. RAC still contains old ITZs between the stone particle and the old mortar and then also ITZs between the old mortar and the new mortar matrix. Such complexity in ITZs makes RAC more susceptible to cracking along this weak zone, particularly when subjected to shear loading. Secondly, after cracking, the shear force across cracks in concrete is mainly transferred by aggregate interlock. Since the virgin aggregate in recycled aggregate is coated by the low-stiffness residual mortar, the effectiveness of the aggregate interlock is decreased. 
Researchers have investigated the shear performance of RAC on both the material- and structural-level. For the material level, the shear strength of RAC has been investigated through direct and indirect shear tests. All the reported results show that the inclusion of recycled aggregate leads to a reduction in shear strength of the RAC. When incorporating $100 \%$ recycled aggregate, researchers found a reduction of shear strength ranging from $10 \%$ to $30 \%$ (Fakitsas et. al, 2012; Rahl, 2007; Rahl and Alrefaei, 2017; Sun et. al, 2018; Xiao et. al, 2012; Wang et. al, 2018). Particularly, in the investigation of Fakitsas et al. (2012) the incorporation of recycled aggregate (replacing all of the virgin aggregate) in high-strength self-consolidating concrete had a negligible influence on the 28-day compressive strength, while shear strength was reduced by approximately $10 \%$. Rahal and Alrefaei (2017) compared the normalized shear strength with respect to the compressive strength of RAC and NAC (normal aggregate concrete) to eliminate the influence of compressive strength. They found a $28 \%$ decrease in shear strength when all of the virgin aggregate was replaced with recycled aggregate. The authors attributed the reduction in shear to be due to the inferior aggregate interlock of recycled aggregate (caused by the existence of residual mortar).

For the structural level, numerous studies have been conducted on the shear strength of recycled aggregate concrete beams. In most of these studies, a decrease in the shear strength of beams made with RCA was observed when compared with beams made with NAC (Arezoumandi et. al, 2015; Arezoumandi et. 2014, 2015; Katkhuda and Shatarat, 2017; Wardeh et. al, 2018; Yu and Yin , 2016 Zahraa, 2011), with the decrease in the shear strength ranging from $10 \%$ to $20 \%$ when all of the virgin coarse aggregate is replaced with RCA. It should be noted that the reduction in shear strength of RAC beams is not only due to a reduction in the concrete compressive strength. For example, Arezoumandi (2014) conducted a statistical data analysis with normalized shear strength on the influence of RCA on the shear strength of beams, and a reduction of $12 \%-14 \%$ in shear strength was also obtained regardless of compressive strength. $\mathrm{Yu}$ and Yin (2016), found that, although the RAC possesses comparable strength to NAC, a $10 \%$ decrease in shear strength was still observed when using $100 \%$ RCA. The authors attributed these phenomena to the inferior aggregate interlock caused by the existence of residual mortar.

There have also been studies that show that the incorporation of RCA has no significant influence on the shear strength of beams (Bilal and Ali, 2017; Fathifazl et. al, 2011; González-Fonteboa and Martínez-Abella, 2007; Knaack and Kurama, 2015; Kim et. al, 2013). However, in these experiments, variables such as aggregate quality and mix proportions were tightly controlled. For example, in the study of Kim et al. (2013) a high-quality RCA with water absorption ratio of 1.67\% was employed; Fathifazl (2011) prepared the RAC with the so-called Equivalent Mortar Volume method, which resulted in a significant change of the mixture proportions and a low workability of concrete. Nevertheless, from an overall point of view, the incorporation of RCA does appear to cause a reduction in the shear performance of reinforced concrete members.

Most investigations have found that there is a negative influence of RCA on the shear strength of reinforced concrete beams (Fakitsas et al., 2012; Xiao et. al, 2012). 
However, these studies stop short of establishing general constitutive models that account for the influence of RCA on the shear resistance. Such a model is needed to facilitate the use of RCA and allow this material to be used in structural applications. For NAC, Vecchio and Collins investigated the stress-strain relationship of cracked concrete by using a two-dimensional panel test. Based on this new stress-strain relationship, an analytical model called the Modified Compression Field Theory (MCFT) was established. The MCFT can accurately predict the response of reinforced concrete when subjected to shear, and has been adopted in several codes, such as Ontario Highway Bridge Design Code, the AASHTO LRFD specifications and the Canadian Standards Association Concrete Design Code. However, this model does not take into account the influence of RCA.

In this introductory study, three reinforced concrete panels are tested to evaluate the influence of RCA on shear behavior. Three different replacement ratios of RCA were used: $0 \%, 25 \%, 50 \%$ and $100 \%$. The panels were reinforced with 2.28 and $0.46 \%$ steel in the longitudinal and transverse directions, respectively. The main objectives of this study is to provide experimental data to check the validity of using the constitutive model of normal aggregate concrete in simulating the behavior of panels when subjected to shear dominant loads. Future work will investigate formulating a new constitutive model for concrete considering the influence of RCA, if necessary.

\section{EXPERIMENTAL PROGRAM}

\section{Materials}

The base concrete mix design consisted of Lafarge Type I/II Portland cement, locallyavailable river sand, and normal coarse aggregate (NCA). RCA was obtained locally from Gary Merlino Construction Company, Inc.

The grading of NCA was measured according to ASTM C136/C136M. To eliminate the influence of the aggregate grading, the grading of RCA was adjusted to be similar to that of NCA. The grading distribution curves of the NCA and RCA are shown in Figure 1. Error! Reference source not found.The density and water absorption ratio of all the aggregates (including sand, NCA and RCA) were tested in accordance with ASTM C127 and ASTM C128, and the test results are listed

Table 1. As can be seen, when compared with NCA, RCA has lower density (2574 $\mathrm{kg} / \mathrm{m}^{3}$ compared to $2734 \mathrm{~kg} / \mathrm{m}^{3}$ ) and significantly higher water absorption ratio $(5.19 \%$ compared to $0.96 \%$ ). This is mainly caused by the existence of the adhered residual mortar.

The reinforcements in both longitudinal and transverse directions are of the same type, and the stress-strain relationship of the reinforcement was tested in accordance with ASTM E8/E8M. To obtain a good load transfer between the shear keys and the panel, the shear keys were anchored to the panels with longitudinal and transverse reinforcement. Therefore, every rebar was fabricated 2 in longer than the edge length, and both ends of each rebar were threaded with a lathe. 


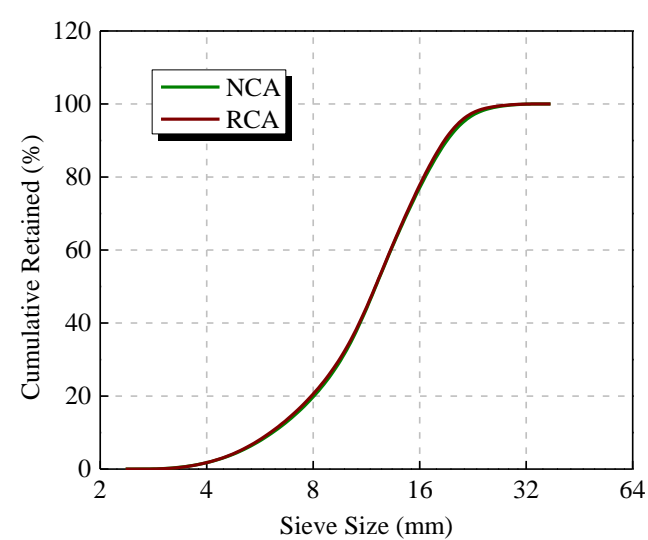

a) Coarse aggregates

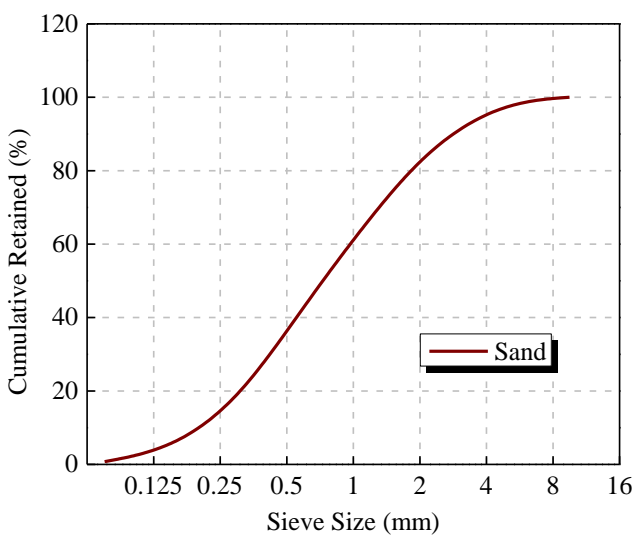

b) sand

Figure 1. Cumulative Percent Retained Versus Sieve Size for Normal Concrete

Aggregate (NCA), Recycled Concrete Aggregate (RCA) and Sand

Table 1. Measured Density and Water Absorption of the Normal Concrete Aggregate (NCA), Recycled Concrete Aggregate (RCA), and Sand

\begin{tabular}{cccc}
\hline $\begin{array}{c}\text { Aggregat } \\
\text { e }\end{array}$ & $\begin{array}{c}\text { Oven-dried density } \\
\left(\mathrm{kg} / \mathrm{m}^{3}\right)\end{array}$ & $\begin{array}{c}\text { SSD density } \\
\left(\mathrm{kg} / \mathrm{m}^{3}\right)\end{array}$ & $\begin{array}{c}\text { Water absorption ratio } \\
(\%)\end{array}$ \\
\hline NCA & 2734 & 2760 & 0.96 \\
RCA & 2574 & 2708 & 5.19 \\
Sand & 2633 & 2670 & 1.41 \\
\hline
\end{tabular}

\section{Concrete Mix Design and Preparation}

The base concrete mix consists of $205 \mathrm{~kg} / \mathrm{m}^{3}$ water, $380 \mathrm{~kg} / \mathrm{m}^{3}$ water, $992 \mathrm{~kg} / \mathrm{m}^{3} \mathrm{NCA}$, and $767 \mathrm{~kg} / \mathrm{m}^{3}$ sand. The RAC was incorporated using the volume replacement method, in which the NCA was replaced with an equal volume of RCA. To keep the effective water to cement ratio of mixtures relatively constant (i.e. $w / c=0.54$ in this test), RCA was used at a saturated-surface-dry (SSD) condition. The SSD condition of RCA was controlled by a 24-hour-immersion in water and an exposure to the air in the laboratory environment for about 2 hours before concrete mixing.

All concrete mixtures were prepared using drum mixers in laboratory. Coupled with each panel specimen, 12 cylinders (nine $6 \times 12$ in cylinders and three $4 \times 8$ in cylinders) were also prepared. With $6 \times 12$ in cylinders, the compressive strength, splitting tensile strength and elastic modulus were measured on the testing day, in accordance with ASTM C39/C39M, ASTM C496/C496M and ASTM C469/C469M, respectively. The $4 \times 8$ in cylinders were adopted in the test for stress-strain relationships of concretes with MTS, in accordance with ASTM C469/C469M. All specimens were demolded after 24 hours, and then cured in the fog room under standard condition until the test age. 


\section{Concrete Panel Reinforcement, Instrumentation and Loading}

Three orthogonally reinforced panels were tested. The panels were $890 \times 890 \times 70 \mathrm{~mm}$ $(35 \times 35 \times 2.75$ in $)$ and loaded with monotonically increasing in-plane pure shear loads using the Panel Tester at the University of Washington. Figure 2 shows steel reinforcement in the panels.

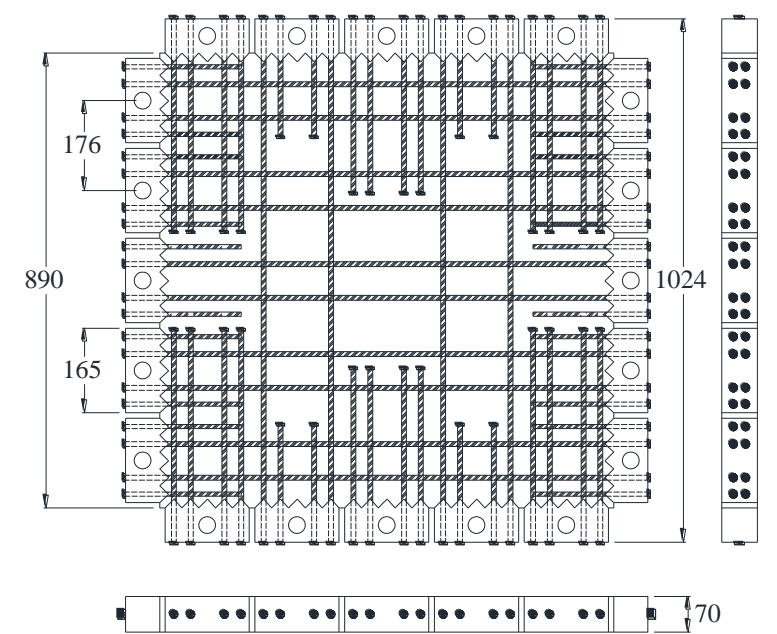

Figure 2. Layout of the Steel Reinforcement in Panel (2.28 and 0.46\% in Longitudinal and Transverse Directions, Respectively.

The panels were instrumented with LED targets fixed to the surface of the panels. The load transducers were connected to pump hoses in both vertical and horizontal directions to monitor and record the load applied to panels. Twenty-five LED targets were fixed to each test panel, forming a grid of sixteen squares at the center of panels, see Figure 3. Through those targets, the longitudinal, transverse and diagonal deformation and strain were measured continuously during the whole test procedure. After the setup of all the instruments, the load was applied until the first crack can be observed, the crack width and position were then recorded. Afterwards, the panels went through approximately five loading steps until the failure of panels. Observed cracks were marked and photographed between every two steps.

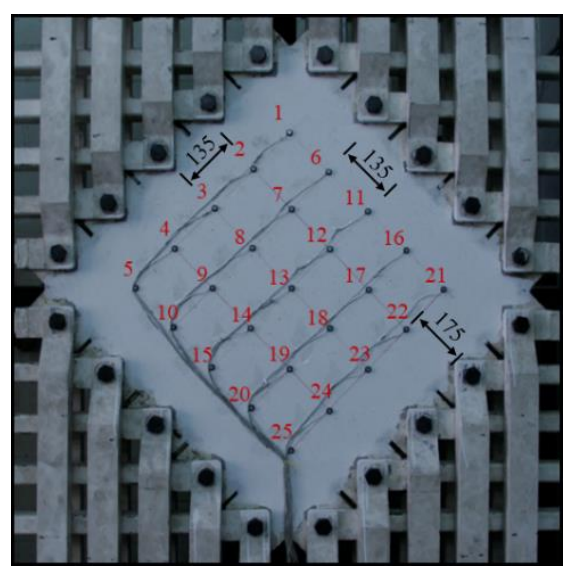

Figure 3. Reinforced Concrete Panel in Load Tester with LED targets 


\section{RESULTS}

Figure 4 presents representative compressive stress versus strain of concrete with normal aggregate (NAC) and with $25,50 \%$ and $100 \%$ of the normal aggregate replaced with recycled concrete aggregate, RAC-25, RAC-50 and RAC-100, respectively. Table 2 presents the measured compressive and tensile material properties and the workability of the concrete. As more content of RCA is incorporated, the modulus and the peak strain would decrease accordingly, which may result in a softened stiffness and a lower load capacity of concrete members. The average compressive strength of the base mix is 43.1 MPa. There is a slight decrease in compressive strength when recycled aggregate is used. The splitting tensile strength of all four concretes is similar. The average elastic modulus of the NAC is $31.2 \mathrm{GPa}$ and the modulus decreases slightly as more recycled aggregate is used to replace virgin aggregate. The slump of the NAC is $180 \mathrm{~mm}$ and the slump increases slightly when more recycled aggregate incorporated.

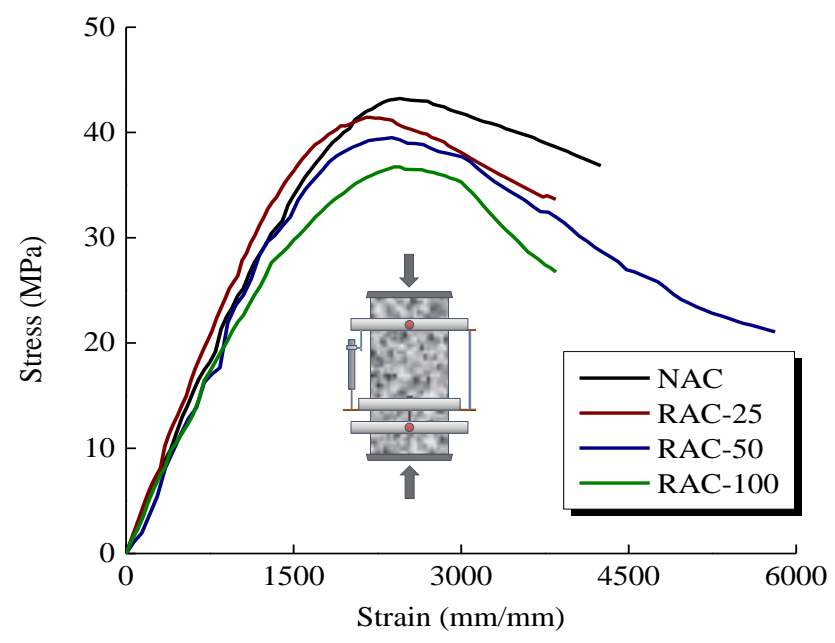

Figure 4. Compressive Stress Versus Strain of Concrete with Normal Aggregate Concrete (NAC) and Concrete with 25, 50\% and 100\% of the NAC Replaced with Recycled Aggregate Concrete (RAC)

Table 2. Material Properties of the Normal Aggregate Concrete (NAC) and Concrete with $25,50 \%$ and $100 \%$ of the NCA replaced with Recycled Aggregate (RCA): Compressive Strength $\left(f_{\mathrm{c}}\right)$, Splitting Tensile Strength $\left(f_{\mathrm{t}}\right)$, Elastic Modulus $\left(E_{\mathrm{c}}\right)$. Results are Average of Three Test Specimens.

\begin{tabular}{lcccc}
\hline Concrete & $\begin{array}{c}\boldsymbol{f}_{\mathbf{c}} \\
(\mathbf{M P a})\end{array}$ & $\begin{array}{c}\boldsymbol{f}_{\mathbf{t}} \\
(\mathbf{M p a})\end{array}$ & $\begin{array}{c}\boldsymbol{E}_{\mathbf{c}} \\
(\mathbf{G p a})\end{array}$ & $\begin{array}{c}\text { Slump } \\
(\mathbf{m m})\end{array}$ \\
\hline \hline NAC & 43.1 & 3.2 & 31.2 & 180 \\
\hline RAC-25 & 41.3 & 3.2 & 28.9 & 180 \\
\hline
\end{tabular}




\begin{tabular}{lcccc}
\hline RAC-50 & 39.5 & 3.4 & 28.4 & 190 \\
\hline $\begin{array}{l}\text { RAC- } \\
100\end{array}$ & 36.8 & 2.9 & 27.1 & 195 \\
\hline
\end{tabular}

Figure 5 shows images of the RAC-50 after the splitting tensile strength test. Figure $5 \mathrm{~b}$ shows enlarged sections of the sample. The top aggregates in the enlarged images (outlined in green) are virgin aggregates and the lower aggregates (outlined in yellow) are the recycled concrete aggregates. The concrete fails around the virgin aggregate, but fractures through the weaker recycled aggregate. The smaller outline within the recycled aggregate shows a virgin aggregate within the recycled aggregate concrete.

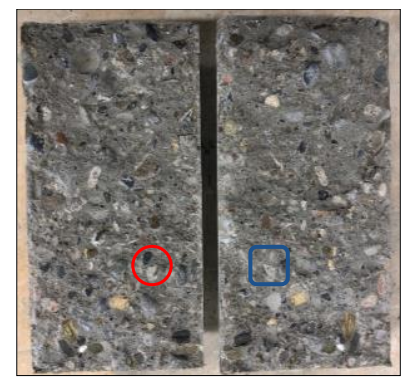

(a)
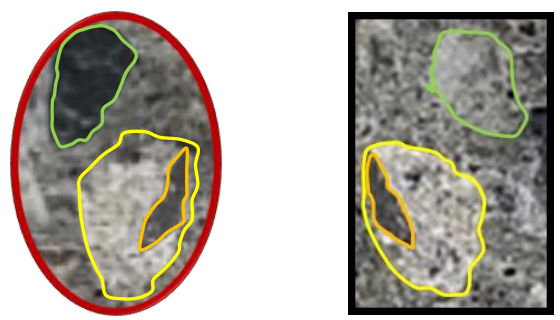

(b)

Figure 5. Pictures after the Splitting Tensile Strength Test of the Recycled Aggregate Concrete in which $50 \%$ of the virgin aggregate is replaced with Recycle Aggregate RAC-50: (a) entire cross section, (b) enlarged image

Figure 6 presents images of four panels at failure state with the peak shear load and the shear strain at the peak load. On each panel, distributed cracks formed during loading. Those initial cracks are about 45 degrees from the longitudinal (1) and transverse (t) directions, and this is reasonable considering that panels were under a pure shear loading condition. Moreover, with higher amounts of RCA, initial cracks appear earlier. In Figure 6a, c and d, a main failure crack can be observed, which is rotated from 45 degrees to a direction that is more perpendicular to the transverse ( $t$ ) direction. This is because the reinforcement ratio in the $t$ direction is much smaller than that in 1 direction (i.e. $0.46 \%$ and $2.28 \%$ for $t$ and 1 directions, respectively). For RAC-25, the ultimate limit state was not reached. This is because the specimen ended up with an edge failure, see Figure $6 \mathrm{~b}$ (a shear block was pulled out before reaching the ultimate load).

Figure 7 illustrates the comparison of the shear response among panels with different replacement ratios of RCA. As can be observed, the stiffness of panels with RCA is similar to that of the panel with NAC. The first turn on the curves indicates the emergence of cracks in concrete. The first turn on curves of concrete with RCA is earlier than that of NAC, and this highlights an earlier crack in concrete with RCA, which is consistent with visual observations during the experiment. 


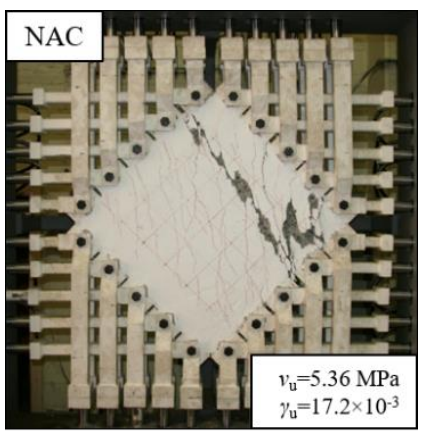

(a) NAC

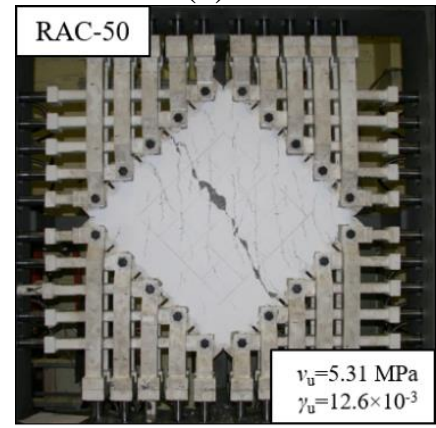

(c) RAC-50

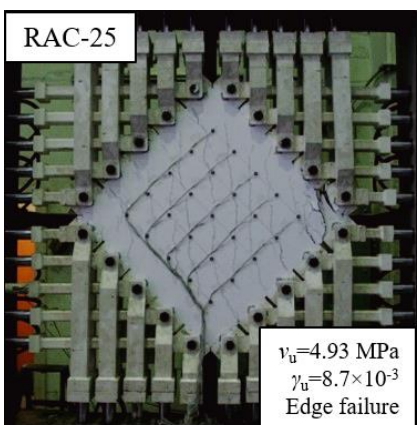

(b) RAC-25

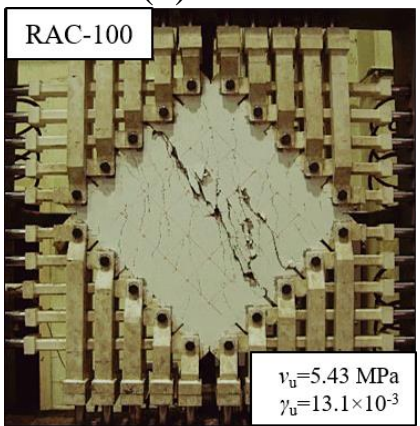

(d) RAC-100

Figure 6. Failure of Reinforced Concrete Panels: (a) Normal Aggregate Concrete (NAC) and (b) Concrete with $25 \%$ of the NCA replaced with Recycled Aggregate (RCA), RAC-25, (c) $50 \%$ of the NCA RCA, RAC-50 and (d) $100 \%$ of the NAC RCA, RAC-100.

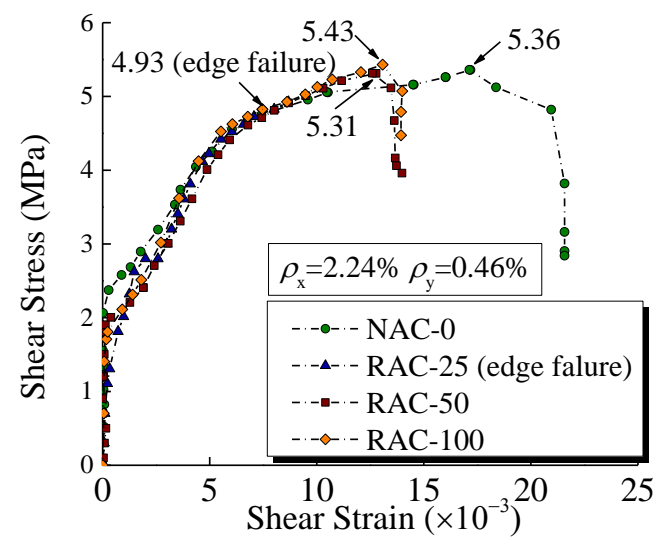

Figure 7. Shear Response of Panels with different content of RCA Normal Aggregate Concrete (NAC) and (b) Concrete with $25 \%$ of the NAC replaced with Recycled Aggregate Concrete (RAC), RAC-25 and (c) 50\% of the NAC RAC, RAC-50.

The response of panels was simulated using Membrane 2000, which was developed for the prediction of the response of reinforced concrete panels subjected to in-plane shear loading using the Modified Compression Field Theory (MCFT) for NAC. Those constitute relationships of steel and concrete obtained by test were adopted in the simulation. The comparison between the predicted and tested results of the shear response is presented in Figure 8. MCFT predicts the response of the NAC reasonably well, particularly the initial stiffness and the first crack. However, once RAC was used, the experimental response deviates from the MCFT. As can be seen, the peak shear 
stress of RAC-50 and RAC-100 is higher than the predicted result and the ductility of all RAC is lower than the prediction of MCFT.

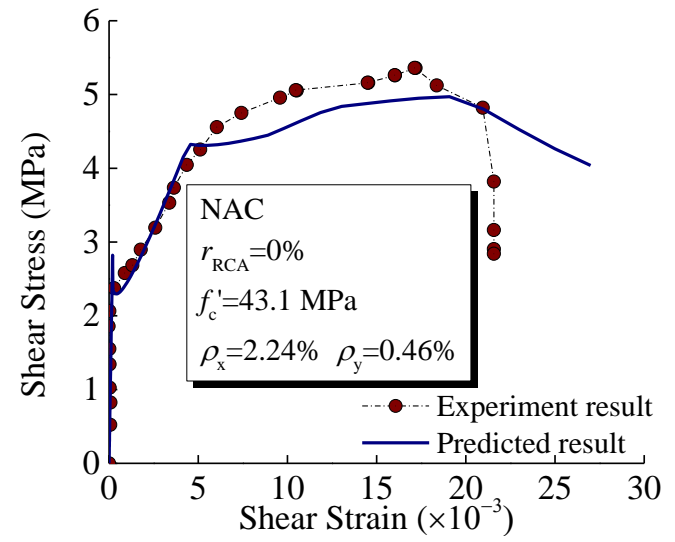

(a)

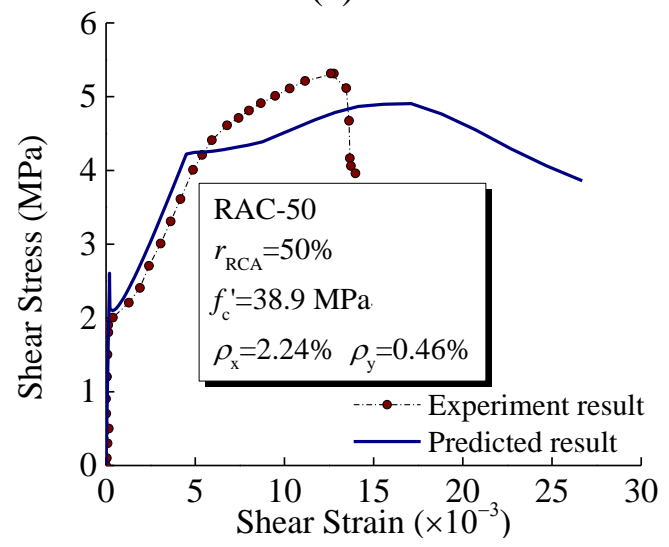

(c)

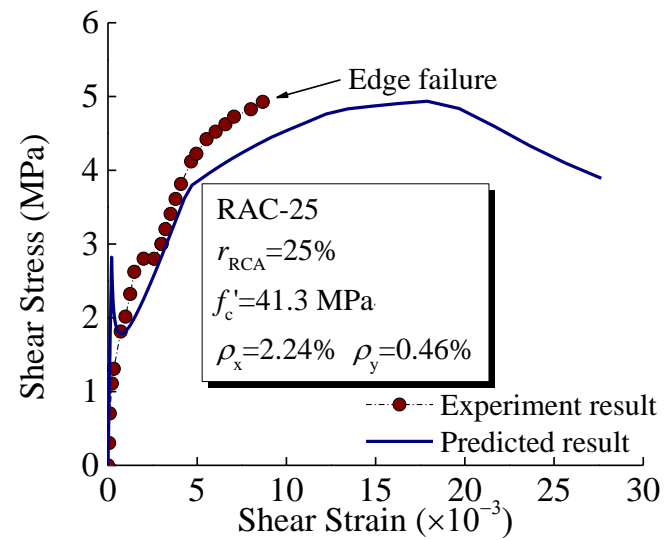

(b)

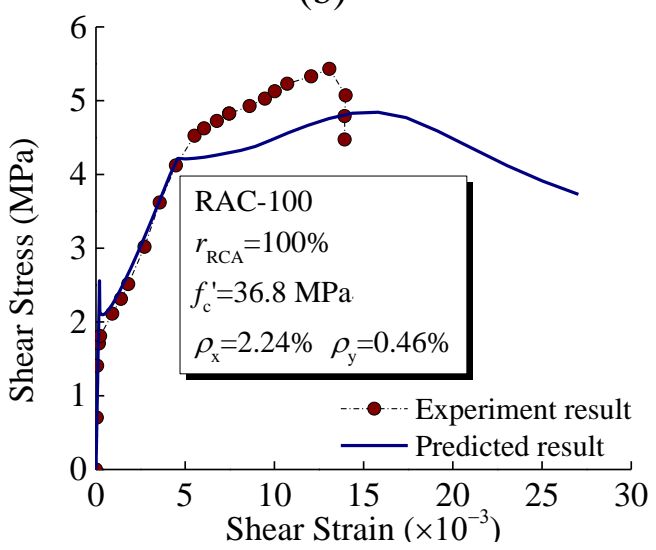

(d)

Figure 8. Comparison of the Predicted and Measured Shear Response of Panels with (a) Normal Aggregate Concrete (NAC) and (b) Concrete with 25\% of the NCA Replaced with Recycled Aggregate (RCA), RAC-25, (c) 50\% of the NCA Replaced, RAC-50, and (d) $100 \%$ of the NCA Replaced, RAC-100.

\section{CONCLUSION}

In this study, the influence of RCA on the performance of reinforced concrete panels was evaluated. The results show that inclusion of RCA in concrete leads to a reduction in compressive strength and elastic modulus, and the slump value increases slightly due to the saturated surface dry condition of RCA Reinforced concrete panels with RCA have a similar shear stiffness but an earlier first crack when compared to NCA. Existing constitutive models predict the shear behavior of NAC reasonably well; however, modifications are needed to more accurately describe the behavior of panels with RAC. Future work will include modifying this model to include the influence of the RAC. 


\section{REFERENCES}

Arezoumandi, M., Drury, J., Volz, J.S., Khayat, K.H. (2015) "Effect of Recycled Concrete Aggregate Replacement Level on Shear Strength of Reinforced Concrete Beams." ACI Materials Journal;112(4).

Arezoumandi, M., Smith, A., Volz, J.S., Khayat, K.H. (2014) “An Experimental Study on Shear Strength of Reinforced Concrete Beams with 100\% Recycled Concrete Aggregate." Construction and Building Materials; 53:612-20.

\section{http://www.rockproducts.com/features/13045-world-aggregates-} market.html\#.W9D7eGhKjIU. accessed October 2018.

Bilal, H., Ali, D. (2017) "Overview of Studies on the Effect of Recycled Aggregates Sourced from Tested Cylinders on Concrete Material and Structural Properties." MATEC Web Conf. 120(1):3007.

Corinaldesi, V. (2010) "Mechanical and Elastic Behaviour of Concretes Made of Recycled-Concrete Coarse Aggregates." Construction and Building Materials. 24(9):1616-20.

Dean, S.W., Liu, J., Chen, B. (2008) "Mechanical Properties of High Strength Concrete with Field-Demolished Concrete as Aggregates.” J. ASTM Int. 5(10):101650.

Fathifazl, G., Ghani, R.A, Burkan, I. O., Abbas, A., Fournier, B., Foo, S. (2011) “Creep and Drying Shrinkage Characteristics of Concrete Produced with Coarse Recycled Concrete Aggregate.” Cement and Concrete Composites. 33(10):1026-37.

Fathifazl, G., Abbas, A., Razaqpur, A.G., Isgor, O.B., Fournier, B., Foo, S. (2009) "New Mixture Proportioning Method for Concrete Made with Coarse Recycled Concrete Aggregate.” J. Mater. Civ. Eng. 21(10):601-11.

Fathifazl, G., Razaqpur A.G., Burkan, I.O., Abbas, A., Fournier, B., Foo, S. (2011) "Shear Capacity Evaluation of Steel Reinforced Recycled Concrete (RRC) Beams." Engineering Structures.33(3):1025-33.

Fakitsas, C.G., Papakonstantinou, P.E.A., Kiousis, P.D., Savva, A. (2012) "Effects of Recycled Concrete Aggregates on the Compressive and Shear Strength of HighStrength Self-Consolidating Concrete." J. Mater. Civ. Eng. 24(4):356-61.

González-Fonteboa, B., Martínez-Abella, F. (2007) "Shear Strength of Recycled Concrete Beams." Construction and Building Materials;21(4):887-93. 
Henry, M., Pardo, G., Nishimura, T., Kato, Y. (2011) "Balancing Durability and Environmental Impact in Concrete Combining Low-Grade Recycled Aggregates and Mineral Admixtures.” Resources, Conservation and Recycling. 55(11):1060-9.

Katkhuda, H., Shatarat, N. (2016) "Shear Behavior of Reinforced Concrete Beams Using Treated Recycled Concrete Aggregate." Construction and Building Materials;125:63-71.

Kim, S.-W., Jeong, C.-Y., Lee. J.-S., Kim, K.-H. (2013) "Size Effect in Shear Failure of Reinforced Concrete Beams with Recycled Aggregate." JJABE;12(2):323-30

Knaack, A.M., Kurama, Y.C. (2015) "Behavior of Reinforced Concrete Beams with Recycled Concrete Coarse Aggregates.” J. Struct. Eng. (3):B4014009.

Kou, S.-C., Poon, C.-S., Agrela, F. (2011) "Comparisons of Natural and Recycled Aggregate Concretes Prepared with the Addition of Different Mineral Admixtures." Cement and Concrete Composites. 33(8):788-95.

Safiuddin, M., Alengaram, U.J., Rahman, M.M., Salam, M.A., Jumaat, M.Z. (2013). "Use of Recycled Concrete Aggregate in Concrete: A Review." Journal of Civil Engineering and Management. 9(6):796-810.

Radonjanin, V., Malešev, M., Marinković, S., Al Malty, A.E.S. (2013) "Green Recycled Aggregate Concrete." Construction and Building Materials. 47:1503-11.

Rahal, K. (2007) "Mechanical Properties of Concrete with Recycled Coarse Aggregate." Building and Environment. 42(1):407-15.

Rahal, K.N., Alrefaei, Y.T. (2017) "Shear Strength of Longitudinally Reinforced Recycled Aggregate Concrete Beams.” Engineering Structures. 145:273-82.

Rahal K. (2017) "Shear Strength of Recycled Aggregates Concrete." Procedia Engineering. 210:105-8.

Sun, C., Xiao, J., Lange, D.A. (2018) "Simulation Study on the Shear Transfer Behavior of Recycled Aggregate Concrete." Structural Concrete. 9(1):255-68.

Xiao, J., Li, W., Fan, Y., Huang X. (2012) "An Overview of Study on Recycled Aggregate Concrete in China (1996-2011)." Construction and Building Materials. 31:364-83.

Xiao, J., Xie, H., Yang, Z.. (2012) "Shear Transfer Across a Crack in Recycled Aggregate Concrete." Cement and Concrete Research. 42(5):700-9. 
Wang, W.-L., Kou, S.-C., Xing, F. (2013) "Deformation Properties and Direct Shear of Medium Strength Concrete Prepared with 100\% Recycled Coarse Aggregates." Construction and Building Materials. 48:187-93.

Wardeh, G., Ghorbel, E., Gomart, H., Fiorio, B., Pliya, P. (2018) "Shear Behavior of Reinforced Recycled Aggregate Concrete Beams." In: Hordijk DA, Luković M, editors. High Tech Concrete: Where Technology and Engineering Meet. Cham: Springer International Publishing; p. 508-515.

Yang, H., Zhao, H., Liu, F. (2018) "Residual Cube Strength of Coarse RCA Concrete After Exposure to Elevated Temperatures." Fire and Materials. 42(4):424-35.

Yu, F., Yin, C. (2016) International Conference on Smart City and Systems Engineering - ICSCSE 2016: Zhangjiajie, Hunan, China, November 25-26, Piscataway, NJ: IEEE.

Zahraa, F.A., Mihilmy, M.T.E., Bahaa, T. (2011) "Experimental Investigation of Shear Strength of Concrete Beams with Recycled Concrete Aggregates.” IJMSI. (4):291. 